\title{
PERANCANGAN PROTOKOL KOMUNIKASI UNTUK JSN (JARINGAN SENSOR NIRKABEL) PADA KAMPUS HIJAU
}

\author{
Nurazizah $^{1)}$, Oky Dwi Nurhayati ${ }^{2)}$, Eko Didik Widianto ${ }^{2)}$ \\ Program Studi Sistem Komputer, Fakultas Teknik, Universitas Diponegoro \\ Jalan Prof. Soedarto, SH, Tembalang, Semarang, Indonesia
}

\begin{abstract}
Environmental conditions in a large area often requires monitoring. For example, in the case of greenhouse used for experimental research cultivation, fertilization experiment, experiment plant resistance, tissue culture experiments, experimental planting of crops in the off-season, the necessary equipment to monitor and control the environmental conditions in order to suit the characteristics of the environment is needed. The size of area to be monitored, making the need for the spread of monitoring equipment at some point so that monitoring environmental conditions can include all the desired area. This is the basis for the design of communication protocols for WSN (wireless sensor networks) on a green campus.

The system consists of hardware that is assembled to the process of measuring PM2.5, $\mathrm{CO}, \mathrm{NO2}, \mathrm{HC}$, light intensity, temperature, and humidity. The system is divided into several sections, hereinafter referred to node. Node on this system can be divided into two functions, namely a sensor node and coordinator node. There are two sensor nodes that will work for data collection in a separate area and sends the data to the coordinator node. Communication between nodes is done using nRF905 module.

The design of communication protocols that are designed to connect between the coordinator node to sensor node is able to run well. It makes the system capable of monitoring temperature and humidity via a web service, so that can know the condition of PM2.5, $\mathrm{CO}, \mathrm{NO2}, \mathrm{HC}$, the intensity of light, temperature and humidity at some point in the range of more than 100 meters.
\end{abstract}

Keywords: Wireless Sensor Networks, Monitor PM2.5, CO, $\mathrm{NO} 2, \mathrm{HC}$, the intensity of light, temperature and humidity, nRF905.

\section{PENDAHULUAN}

Pencemaran udara dewasa ini semakin menampakkan kondisi yang sangat memprihatinkan. Sumber pencemaran udara dapat berasal dari berbagai kegiatan antara lain industri, transportasi, perkantoran, dan perumahan. Berbagai kegiatan tersebut merupakan kontribusi terbesar dari pencemar udara yang dibuang ke udara bebas. Dampak dari pencemaran udara tersebut adalah menyebabkan penurunan kualitas udara, yang berdampak negatif terhadap kesehatan manusia. ${ }^{[1]}$

Pencemaran udara merupakan masalah bersama yang membutuhkan sinergi semua elemen masyarakat, termasuk didalamnya adalah civitas akademika. Sebagai kalangan akademisi, para pemangku kepentingan kampus turut andil dalam memantau kondisi dilingkungan kampus, sehingga untuk memantau pencemaran udara di lingkungan kampus para pemangku mengangkat sebuah tema yang berjudul kampus hijau.
Pada kasus kampus hijau, diperlukan pemantauan terhadap kondisi lingkungan sekitar kampus. Kondisi lingkungan yang dipantau berupa parameter - parameter lingkungan seperti konsentrasi hidro karbon (HC), karbon monoksida (CO), nitrogen oksida (NO), kepadatan partikel debu, intensitas cahaya, kelembaban udara dan suhu lingkungan kampus. ${ }^{[2]}$

Luasnya lahan lingkungan kampus yang akan dipantau, membuat kondisi lingkungan pada beberapa titik tidak selalu sama. Hal ini menjadikan perlu adanya pemantauan kondisi lingkungan yang bisa mencakup seluruh area yang dinginkan. Hal ini yang menjadikan dasar untuk melakukan pengembangan teknologi dalam hal pemantauan kondisi lingkungan di suatu area yang luas. ${ }^{[3]}$

Penggunaan sistem komunikasi nirkabel (wireless) sebagai media komunikasi pada sistem jaringan komputer semakin populer sekarang ini. Aplikasi teknologi nirkabel membuat informasi dan komunikasi menjadi cepat dan mudah. Teknologi yang akan dirancang adalah sebuah sistem pemantauan konsentrasi hidro karbon (HC), karbon monoksida (CO), nitrogen oksida (NO), kepadatan partikel debu, intensitas cahaya, kelembaban udara dan suhu di beberapa titik area yang berbeda. Sistem ini mendukung sensor di beberapa titik, yang hasil nya akan dikirimkan ke komputer secara nirkabel. Sedangkan sistem pemantau alat ini ditampilkan pada halaman web browser.

Komunikasi yang digunakan dalam sistem ini adalah jaringan sensor nirkabel menggunakan nRF905. Perbandingan nRF905 dengan modul komunikasi nirkabel lainnya, misalnya nRF24L01 adalah harga dari nRF905 lebih mahal, tapi jangkauannya lebih jauh yaitu 100 meter untuk nRF24L01+ dan 1000 meter untuk nRF905. Namun, dengan kebutuhan jangkauan komunikasi yang akan diterapkan pada area yang luas, misalnya pada lingkungan kampus, menjadi alasan pemilihan modul nRF905 sebagai pengoptimalan fungsional yang diperlukan.

\section{METODELOGI PENELITIAN}

Metode pengembengan yang digunakan mengacu pada kerangka kerja metode "waterfall". Waterfall mengusulkan pendekatan kepada pengembangan yang sistematik dan sekuensial yang dimulai pada tingkat dan kemajuan sistem pada seluruh analisis, desain, kode, testing dan perawatan. Model waterfall melingkupi aktivitas-aktivitas seperti Gambar 1 berikut. 


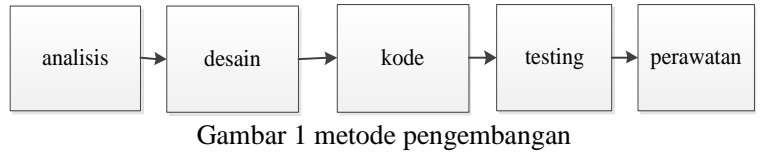

Setiap tahapan merupakan sebuah proses yang menghasilkan keluaran, dimana setiap tahapan harus diselesaikan terlebih dahulu sebelum melanjutkan fase selanjutnya. Tahap analisis dilakukan untuk mengidentifikasikan dan mengevaluasi permasalahnpermasalahan, hambatan-hambatan yang terjadi dan kebutuhan-kebutuhan yang diharapkan sehingga dapat diusulkan perbaikan-perbaikan. Tahap desain merupakan tahap mengubah kebutuhan-kebutuhan menjadi bentuk karakteristik yang di mengerti, tahap ini bertujuan untuk memberikan gambaran apa yang seharusnya dikerjakan. Tahap kode merupakan tahap mengubah bentuk desain menjadi bentuk yang dapat dimengerti oleh mesin (komputer). Tahap testing dilakukan penggabungan modul-modul yang telah dibuat dan dilakukan pengujian ini untuk mnegetahui apakah yang telah dibuat sesuai dengan desain dan masih terdapat kesalahan atau tidak. Tahap perawatan merupakan tahap terakhir waterfall. Perawatan termasuk dalam memperbaiki kesalahan yang tidak ditemukan pada langkah sebelumnya. Perbaikan implementasi unitsistem dan peningkatan jasa sistem sebagai kebutuhan baru. ${ }^{[4]}$

\section{PERANCANGAN SISTEM}

\subsection{Idenstifikasi kebutuhan sistem}

Indentifikasi kebutuhan sistem membahas tentang kebutuhan fungsional dan kebutuhan non fungsional.

3.1.1 Kebutuhan fungsional

Kebutuhan fungsional dalam perancangan sistem adalah sebagai berikut:

1. Sistem menggunakan mikrokontroler ATmega 2560 pada papan Arduino sebagai pusat kendali (node sensor) untuk membaca masukan analog dari sensor dan mengubah menjadi sinyal digital.

2. Sistem mampu mengirim data dari node sensor ke node koordinator secara periodik.

3. Sistem menggunakan mikrokontroller ATMega328 pada papan Arduino sebagai pusat kendali (node kordinator) untuk membaca masukan sinyal digital dan mengubah menjadi sinyal analog dari mikrokontroler Atmega2560.

4. Sistem mampu menerima data dari node sensor dan mengelola masukan dari node sensor untuk ditampilkan ke sistem informasi.

\subsubsection{Kebutuhan nonfungsional}

Kebutuhan non fungsional dalam perancangan sistem meliputi spesifikasi perangkat keras dan perangkat lunak. Spesifikasi tersebut adalah sebagai berikut:

1. Sistem berupa papan sirkuit cetak yang didesain untuk dapat dipasang dengan papan Arduino Mega 2560.

2. Sistem berupa papan sirkuit cetak yang didesain untuk dapat dipasang dengan papan Arduino uno dan Ethernet Shield.
3. Bahasa pemrograman yang digunakan untuk pengembangan sistem adalah bahasa $\mathrm{C}$ yang terapkan pada perangkat lunak aplikasi Arduino IDE.

4. Aplikasi EAGLE 7.4.0 yang digunakan untuk mendesain papan sirkuit yang dipasang pada Arduiino mega 2560 dan dengan Arduino uno yang terhubung dengan Ethernet shield.

\subsection{Perancangan Perangkat Keras}

Proses perancangan perangkat keras menjabarkan rancangan perangkat keras yang akan digunakan untuk membangun sistem. Mulai dari perangkat keras utama yang dibutuhkan sistem hingga instrumen elektronika pendukungnya. Gambar 2 merupakan diagram blok perangkat keras sistem yang menunjukkan rancangan perangkat keras sistem.

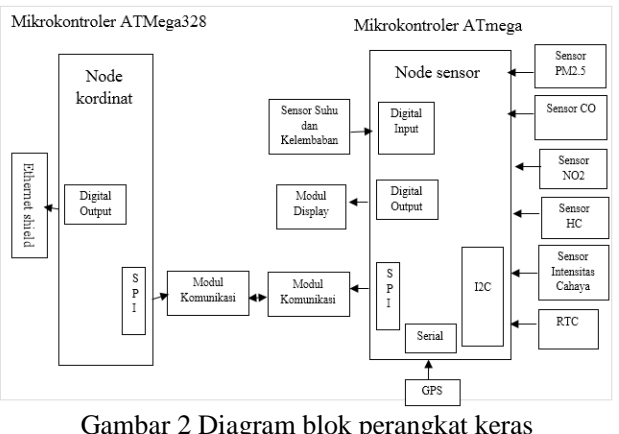

Pusat kendali sistem menggunakan mikrokontroler ATmega 2560 pada papan Arduino Mega 2560. Komponen yang terhubung dengan sistem diantaranya adalah GP2Y1010AU0F sebagai sensor PM 2.5, TGS 2600 sebagai sensor CO, TGS 2201 sebagai sensor NO2, SHT11 sebagai sensor suhu dan kelembaban, BH1750 sebagai sensor intensitas cahaya, Modul DS1307 sebagai RTC (Real Time Clock), dan penerima GPS Ublox NEO $6 \mathrm{M}$ sebagai penerima koordinat GPS. Sedangkan untuk modul Display menggunakan display dot matrik p10 dan untuk modul komunikasi menggunakan modul radio nRF905. Tabel 1 menunjukkan antarmuka pin arduino mega dengan komponen pada sistem.

Tabel 1 Antarmuka pin dengan komponen mikrokontroler Atmega 2560

\begin{tabular}{|c|l|l|l|}
\hline No & $\begin{array}{l}\text { Antarmuka Pin } \\
\text { Arduino }\end{array}$ & $\begin{array}{l}\text { Antarmuka Pin } \\
\text { nRF905 }\end{array}$ & $\begin{array}{l}\text { Antarmuka Pin } \\
\text { Komponen }\end{array}$ \\
\hline 1 & 2 & & SDA SHT11 \\
\hline 2 & 3 & & SCL SHT11 \\
\hline 3 & 4 & & LED PM2.5 \\
\hline 4 & 6 & & Modul Display \\
\hline 5 & 7 & & Modul Display \\
\hline 6 & 8 & & Modul Display \\
\hline 7 & 9 & & Modul Display \\
\hline 8 & 11 & & Modul Display \\
\hline 9 & 13 & & Modul Display \\
\hline 10 & $18($ TX1 $)$ & & RX NEO6M \\
\hline
\end{tabular}




\begin{tabular}{|l|l|l|l|}
11 & $19(\mathrm{RX} 1)$ & & TX NEO6M \\
\hline 12 & 20 (SDA) & & $\begin{array}{l}\text { SDA RTC dan } \\
\text { Sensor Intensitas } \\
\text { Cahaya }\end{array}$ \\
\hline 13 & $21(\mathrm{SCL})$ & & $\begin{array}{l}\text { SCL RTC dan } \\
\text { Sensor Intensitas } \\
\text { Cahaya }\end{array}$ \\
\hline 14 & 22 & & DIP Switch \\
\hline 15 & 23 & & DIP Switch \\
\hline 16 & 24 & & DIP Switch \\
\hline 17 & 25 & & DIP Switch \\
\hline 18 & $50(\mathrm{MOSI})$ & 11 (MOSI) & Modul Komunikasi \\
\hline 19 & $51(\mathrm{MISO})$ & 12 (MISO) & Modul Komunikasi \\
\hline 20 & $52(\mathrm{SCK})$ & 13 (SCK) & Modul Komunikasi \\
\hline 21 & $53(\mathrm{SS})$ & 6 & Modul Komunikasi \\
\hline 22 & A0 & & Input Analog PM2.5 \\
\hline 23 & A1 & & Input Analog CO \\
\hline 24 & A2 & & Input Analog NO2 \\
\hline 25 & A3 & & Input Analog HC \\
\hline
\end{tabular}

Sistem menggunakan beberapa pin yang tersedia pada papan Arduino Mega 2560. Diantaranya adalah empat pin input analog untuk keluaran analog dari sensor, satu pasang pin serial untuk penerima koordinat GPS, $\mathrm{I}^{2} \mathrm{C}$ yaitu pin SDA dan SCL untuk modul RTC dan sensor intensitas cahaya, dan SPI yaitu pin MOSI, MISO, SCK, dan SS untuk modul komunikasi radio (nRF905). Pada tabel 2 menunjukkan antarmuka pin arduino uno dengan komponen pada sistem.

Tabel 2 Antarmuka pin dengan komponen mikrokontroler Atmega328

\begin{tabular}{|l|l|l|l|}
\hline No & Pin Arduino & Pin Ethernet & \multicolumn{1}{|c|}{ Pin nRF905 } \\
\hline 1 & Pin digital 6 & & CSN \\
\hline 2 & Pin digital 7 & & CE \\
\hline 3 & $\begin{array}{l}\text { Pin digital } \\
10\end{array}$ & Pin digital 1 & \\
\hline 4 & $\begin{array}{l}\text { Pin digital } \\
11\end{array}$ & Pin digital 2 & MOSI \\
\hline 5 & $\begin{array}{l}\text { Pin digital } \\
12\end{array}$ & Pin digital 3 & MISO \\
\hline 6 & $\begin{array}{l}\text { Pin digital } \\
13\end{array}$ & Pin digital 4 & SCK \\
\hline
\end{tabular}

Sistem menggunakan beberapa pin yang tersedia pada papan Arduino Mega 328. Diantaranya adalah SPI yaitu pin MOSI, MISO, SCK, dan SS untuk modul komunikasi radio nRF905 dan Ethernet.

\section{A. Mikrokontroler}

Mikrokontroler pada sistem ini menggunakan ATmega 2560 dengan papan Arduino Mega 2560 dan ATMega328 dengan papan Arduino Uno. Papan Arduino Mega 2560 berfungsi mengolah data masukan dari sensor, RTC dan GPS. Papan Arduino Uno berfungsi menerima data masukan dari nRF905 yang terhubung dengan papan Arduino Mega 2560 yang kemudian mengirimkan data yang diterima ke sistem informasi menggunakan Ethernet Shield.

\section{B. Modul Komunikasi nRF905}

modul komunikasi nRF905 merupakan modul komunikasi yang digunakan sebagai penghubung antara node sensor dan node kordinator. Pada node sensor modul komunikasi sinyal digital dari sensor yang kemudian di kirim ke node kordinator dimana pada node kordinator modul komunikasi akan menerima sinyal digital. Dibagian node sensor modul komunikasi memiliki 4 kaki yang terhubung dengan mikrokontroler Atmega 2560 dan satu antena dan dibagian node kordinator memiliki 5 kaki yang terhubung komponen mikrokontroler Atmega328.

\section{Arduino Ethernet Shield}

Arduino Ethernet Shield adalah modul yang berfungsi menghubungkan Arduino board dengan jaringan internet, karna berdasar pada Wiznet W5100 ethernet chip. Arduino Ethernet Shield terdapat pada sisi kordinator dimana disambungkan dengan kabel network RJ45. Arduino Ethernet Shield memiliki 4 kaki yang terhubung dengan mikrokontroler Atmega328 pada papan Arduino Uno.

\subsection{Perancangan Paket Transmisi}

Perancangan paket transisi akan menjelaskan data rate aktual pada nRF905. Paket transmisi pada nRF905 terdiri dari sebuah frame, dimana pada frame tersebut terdapat preamble yang berfungsi untuk melakukan sinkronisasi dengan pihak penerima, address yang berfungsi untuk menandakan alamat tujuan kemana frame akan dikirimkan, payload yang merupakan data yang akan di transmisikan dan CRC yang menyediakan verifikasi untegritas bis terhadapa keseluruhan frame yang bersangkutan. Gambar 3 merupakan bentuk format paket transmisi pada nRF905.

\begin{tabular}{|c|c|c|c|}
\hline $\begin{array}{c}\text { Preamble } \\
10 \text { bit }\end{array}$ & $\begin{array}{c}\text { Address } \\
4 \text { bytes }\end{array}$ & $\begin{array}{c}\text { Payload } \\
47 \text { bytes }\end{array}$ & $\begin{array}{c}\text { CRC } \\
2 \text { bytes }\end{array}$ \\
\hline \multicolumn{3}{|c|}{ Gambar 3 bentuk format paket transmisi pada nRF905 }
\end{tabular}

Pada format paket transmisi terdapat payload yang berukuran 47 byte, dimana pada sistem ini data yang akan dikirimkan id node, GPS, sensor Dust, NO2, CO, temperatur, Humidity, LUX, dan RTC, dimana data dikirim dalam bentuk array (urutan). Gambar 4 merupakan bentuk format paket data pada pengguna pesan.

\begin{tabular}{|c|c|c|c|c|c|c|c|}
\hline $\begin{array}{l}\text { Id } \\
\text { node } \\
2 \text { byte }\end{array}$ & $\begin{array}{l}\text { Temperature } \\
7 \text { byte }\end{array}$ & $\begin{array}{l}\text { RH } \\
4 \\
\text { byte }\end{array}$ & $\begin{array}{l}\text { Dust } \\
5 \\
\text { byte }\end{array}$ & $\begin{array}{l}\text { Lux } \\
5 \\
\text { byte }\end{array}$ & $\begin{array}{l}\text { CO } \\
4 \text { byte }\end{array}$ & $\begin{array}{l}\mathrm{NO} 2 \\
4 \\
\text { byte }\end{array}$ & $\begin{array}{l}\text { RTC } \\
16 \\
\text { byte }\end{array}$ \\
\hline
\end{tabular}

Gambar 4 bentuk format paket data pada pengguna pesan 


\subsection{Perancangan Perangkat Lunak}

\subsubsection{Node Sensor}

Perancangan perangkat lunak akan menjelaskan tahapan dalam pembuatan sistem node sensor berupa program yang mengendalikan perangkat keras. Sistem mampu mengirimkan keadaan lingkungan dari keluaran sensor, membaca waktu sesuai dengan RTC yang terpasang, dan mengirim data. Gambar 5 merupakan diagram alir untuk perancangan program secara umum.

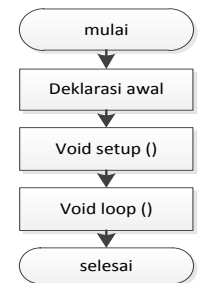

Gambar 5 diagram alir untuk perancangan program secara umum node sensor

Pada Gambar 5 yang pertama dilakukan sistem adalah deklarasi awal kemudian setelah melakukan deklarasi awal, sistem melakukan proses void $\operatorname{setup(),~kemudian}$ setelah melakukan void setup () sistem melakukan prose loop ().

Pada proses deklarasi awal sistem melakukan proses memanggil pustaka yaitu nRF905 dan SPI, kemudian melakukan proses mendefinisikan id yang digunkan oleh node sensor dan node koordinator (server), setelah itu mendeklarasikan tipe data yang akan digunkan untuk sensor Dust, CO, NO2, temperature, Humidity, lux. Gambar 6 proses deklarasi awal node sensor.

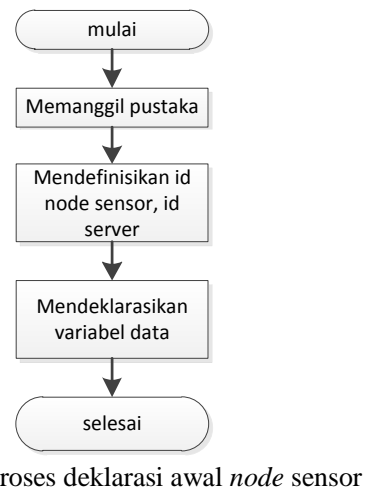

Setelah melakukan proses deklarasi awal, kemudian node sensor melakukan proses setup (). Pada proses ini pertama yang dilakukan adalah proses inisialisasi perangkat nRF905, kemudian inisialisasi komunikasi serial dengan menggunkan baud rate 9600 bps lalu melakukan inisialisasi waktu. Gambar 7 proses setup () node sensor.

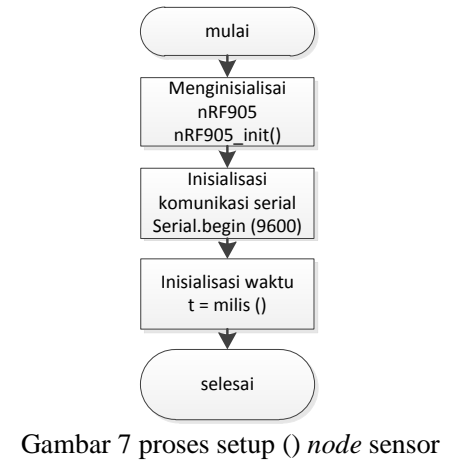

Setelah melakukan proses setup () selanjutnya adalah melakukan proses loop. Dimana proses loop merupakan proses yang dilakukan secara terus menerus selama sistem tersebut dijalankan. Proses pertama yang dilakukan pada proses loop adalah membaca data sensor sensor suhu, RH, lux, Dust, NO2, CO dan RTC kemudian akan menerima data, setelah menerima data nRF905 akan melakukan pengiriman data setelah mendapat data_packet $[0]==0 \times C C$ dengan kondisi send_packet_data $=1$. Gambar 8 proses Loop node sensor.

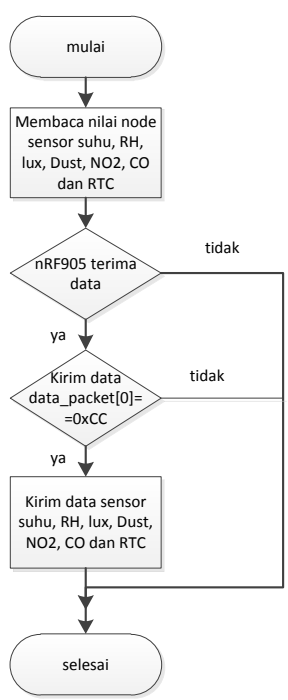

Gambar 8 proses Loop node sensor

\subsubsection{Node Koordinator}

Perancangan perangkat lunak akan menjelaskan tahapan dalam pembuatan sistem node koordinator berupa program yang mengendalikan perangkat keras. Sistem mampu menerima keadaan lingkungan dari keluaran sensor, menerima waktu sesuai dengan RTC yang terpasang, dan mengirim data ke browser. Gambar 9 merupakan diagram alir untuk perancangan program node koordinator secara umum. 


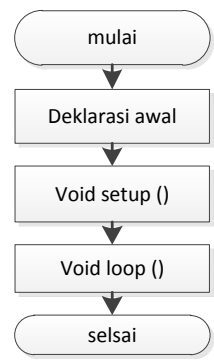

Gambar 9 diagram alir untuk perancangan program node koordinator secara umum

Pada Gambar 9 yang pertama dilakukan sistem adalah deklarasi awal kemudian setelah melakukan deklarasi awal, sistem melakukan proses void setup(), kemudian setelah melakukan void setup () sistem melakukan prose loop ().

Pada proses deklarasi awal sistem melakukan proses memanggil pustaka yaitu nRF905, SPI, Ethernet Shield, kemudian melakukan proses mendefinisikan jumlah device, mendefinisikan id yang digunakan oleh node sensor dan node koordinator (server), setelah itu mendeklarasikan tipe data yang akan digunakan untuk sensor Dust, CO, NO2, temperature, Humidity, lux, dan menyeting urutan device. Gambar 10 proses deklarasi awal node sensor.

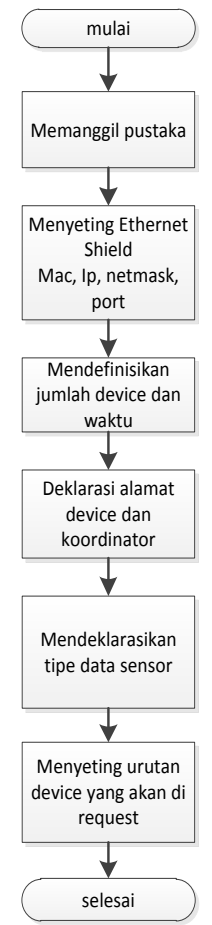

Gambar 10 proses deklarasi awal node koordinator

Setelah melakukan proses deklarasi awal, kemudian node sensor melakukan proses setup (). Pada proses ini pertama yang dilakukan adalah proses inisialisasi perangkat nRF905, mengatur ututan device yang akan di mintain data, kemudian inisialisasi komunikasi serial dengan menggunkan baud rate 9600 bps lalu inisialisasi Ethernet. Gambar 11 proses setup () node sensor.

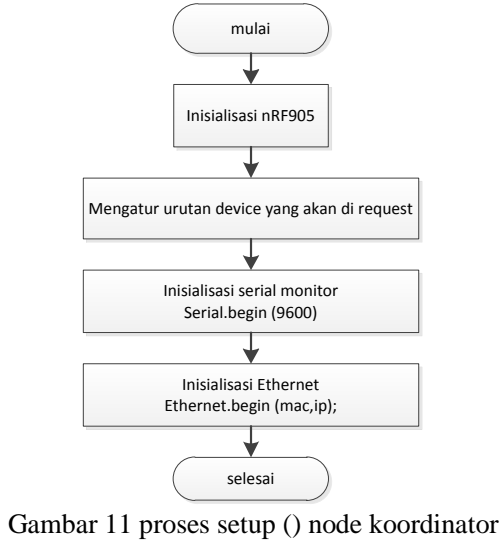

Setelah melakukan proses setup () selanjutnya adalah melakukan proses loop. Pada proses loop node koordinator akan melihat apakah ada client yang aktif atau tidak lalu akan merespon data ke client, jika ada client maka akan merespon data ke client lalu meminta data data ke device dengan pesan "packet_data_ready $=0$ " lalu menunggu hingga waktu sampe dengan batas t, jika mencapai batas $\mathrm{t}$ maka akan menerima balasan "packet_data_ready $=2$ " dan yang kemudian mencetak ke serial monitor bahwa "timeout" lalu mencetak ke browser "failure",jika jika ada balasan "packet_data_ready $=1$ " maka lihat apakah ada data sensor dust, CO, NO2, yemoerature, humidity, lux dan RTC, lalu mencetak ke serial monitor dan browser dengan isi data sensor dust, $\mathrm{CO}, \mathrm{NO} 2$, yemoerature, humidity, lux dan RTC lalu data di update. Gambar 12 prosen Loop node koordinator.

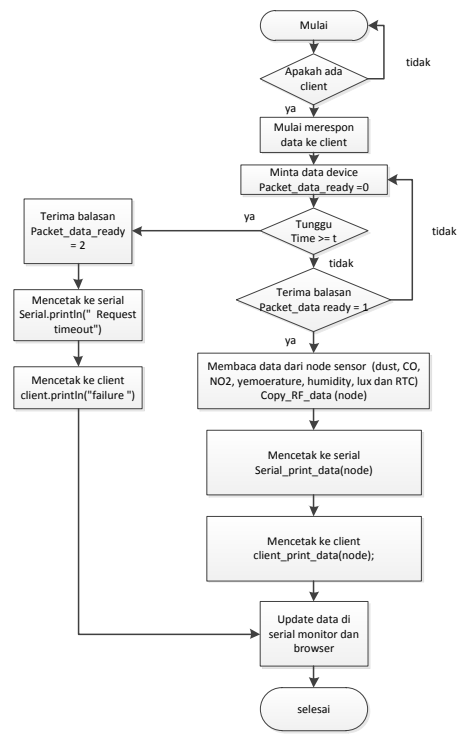

Gambar 12 proses Loop node koordinator

\section{IMPLEMENTASI DAN PENGUJIAN}

Implementasi sistem terdiri dari keseluruhan perangkat keras yang dirangkai untuk proses pengukuran PM2.5, CO, NO2, HC, intensitas cahaya, suhu dan kelembapan pada beberapa titik di area tertentu. Sistem ini terdiri dari node sensor dan node koordinator. Dalam sistem ini, ada 3 node sensor yang akan berfungsi untuk melakukan pengambilan data $\mathrm{PM} 2.5, \mathrm{CO}, \mathrm{NO} 2, \mathrm{HC}$, 
intensitas cahaya, suhu dan kelembapan pada area terpisah yang telah ditentukan.

Node koordinator terdiri dari arduino uno beserta Ethernet Shield dan nRF905 sebagai modul komunikasi dan kabel USB beserta kabel UTP. Sedangkan node sensor terdiri Arduino uno beserta nRF905.

Perangkat keras pertama yang diimplementasikan adalah papan sirkuit elektronik tempat komponen-komponen saling terhubung untuk menjadi sebuah sistem perangkat keras yang dibutuhkan, sesuai dengan port-port yang digunakan seperti yang dijelaskan dalam perancangan sistem pada Gambar 13 menunjukkan desain papan sirkuit elektronik.

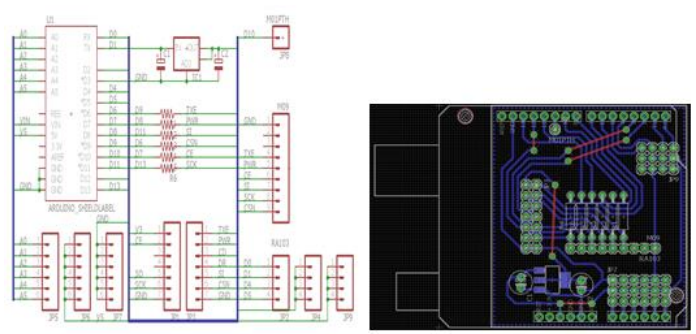

Gambar 13 Desain papan sirkuit elekronik

Setelah papan sirkuit elektronik selesai dibuat, kemudian komponen-komponen yang dibutuhkan dikumpulkan dan dipasang pada papan sirkuit elektronik dengan benar sesuai dengan perancangan sebelumnya. Pada Gambar 14 dan Gambar 15 ditunjukkan perbandingan gambar rancangan papan sirkuit elektronik dengan gambar setelah seluruh komponen dipasang pada papan sirkuit elektronik. Selanjutnya Gambar 16 menunjukkan tampilan perangkat keras pada node koordinator dan Gambar 17 menunjukkan tampilan perangkat keras pada node sensor.

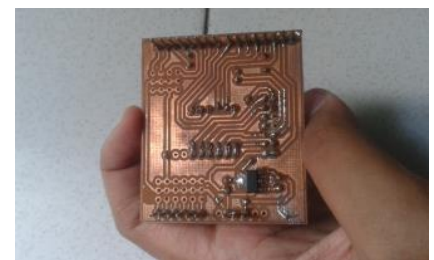

Gambar 14 Papan sirkuit elektronik yang sudah bisa digunakan

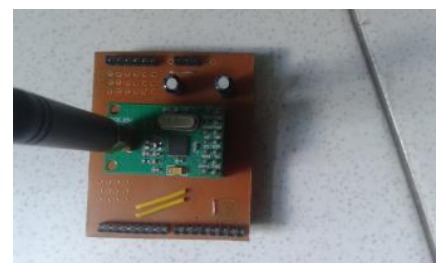

Gambar 15 Pemasangan komponen pada papan sirkuit elektronik

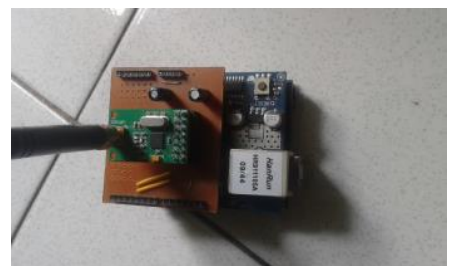

Gambar 16 Tampilan perangkat keras node koordinator

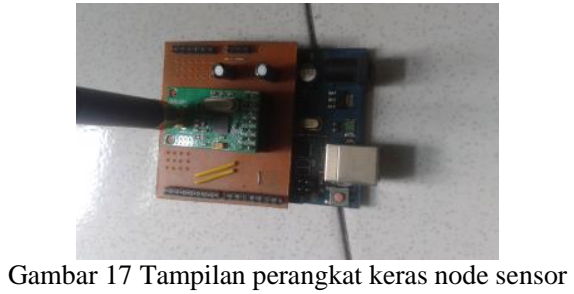

Implementasi perangkat lunak dilakukan dengan memprogram masing-masing node, yaitu node koordinator dengan node sensor. Pemrograman dilakukan sesuai dengan fungsi dari node masing-masing. Program tersebut kemudain diunggah ke papan Arduino Uno.

\subsection{Rencana Pengujian Alat}

Pengujian akan dibagi menjadi 2 bagian, yang pertama dalah pengujian fungsional dan pengujian keandalan sistem.

\subsubsection{Pengujian fungsional}

Pengujian ini dilakukan dengan cara menjalankan semua sub sistem, baik node koordinator yang terhubung dengan web browser dan node sensor 1, node sensor 2, dan node sensor 3. Dalam pengujian ini akan dilakukan dengan dua metode. Metode pertama akan dilakukan pengamatan 3 node sensor dapat membaca data sensor PM2.5, CO, NO2, HC, intensitas cahaya, suhu dan kelembapan lalu mengirimkannya ke node koordinator dan node koordinator yang terhubung ke internet menerima data sensor $\mathrm{PM} 2.5, \mathrm{CO}, \mathrm{NO} 2, \mathrm{HC}$, intensitas cahaya, suhu dan kelembapan dan mengirim ke web browser.

Pengujian metode kedua akan dilakukan pengamatan dengan cara menambah node sensor yang akan di terima oleh node koordinator dalam waktu 1 detik dan di kirim ke web browser setiap 5 detik. Hasil dari setiap penambahan node sensor akan dicatat kedalam tabel hasil pengujian penambahan node sensor .

\subsubsection{Pengujian keandalan sistem}

Pengujian ini dilakukan di sebuah area terbuka dengan menjalankan sistem, baik node koordinator dan node sensor. Pengujian akan dilakukan dengan pengamatan jangkauan pengiriman terjauh antara node sensor dengan node koordinator dimana node sensor mengirim data sebnayak 10 data dan jarak antara node sensor dan node koordinator akan diperpanjang dengan setiap 30 meter sekali dan hasil pengamatan jangkauan terjauh antara node sensor dan node koordinator akan dicatat kedalam tabel hasil pengujian.

\subsection{Pengujian alat}

Dalam pembahasan ini, dilakukan pengujian terhadap funsional, terdapat jenis pengujian yaitu pengujian fungsional dan pengujian keandalan sistem.

\subsection{1 pengujian fungsi}

metode pengujian pertama adalah 3 node sensor dapat mengirim data ke node koordinator dan web 
browser. Pengujian ini dapat dikatakan berhasil apabila node sensor dapat menbaca data sensor PM2.5, CO, NO2, $\mathrm{HC}$, intensitas cahaya, suhu dan kelembapan dan mengirimkan ke node koordinator berupa id node sensor dan data sensor PM2.5, CO, NO2, HC, intensitas cahaya, suhu dan kelembapan setelah mendapat pesan comaand "packet_data_ready $=0$ "dari node koordinator. Lalu node koordinator dapat menerima data sensor PM2.5, CO, $\mathrm{NO} 2, \mathrm{HC}$, intensitas cahaya, suhu dan kelembapan dan mengirimkan ke web browser. Dan jika node sensor gagal membaca data sensor PM2.5, CO, NO2, HC, intensitas cahaya, suhu dan kelembapan maka node koordinator akan mendapatkan status "request timeout" dan web browser menampilkan status "failure". Gambar 18, Gambar 19, Gambar 20 menunjukkan node sensor 1, node sensor 2, node sensor 3 membaca data sensor PM2.5, CO, $\mathrm{NO} 2, \mathrm{HC}$, intensitas cahaya, suhu dan kelembapan dan mengirimkan ke node koordinator. Gambar 21 menunjukkan bahwa node koordinator mendapat data sensor PM2.5, CO, NO2, HC, intensitas cahaya, suhu dan kelembapan dari node sensor dan mengirimkan ke web browser. Gambar 22 node koordinator memberikan pesan "request timeout" ke web browser dan di web browser tampil pesan "failure" yang menandakan bahwa node sensor tidak mengirimkan data sensor PM2.5, CO, NO2, $\mathrm{HC}$, intensitas cahaya, suhu dan kelembapan.

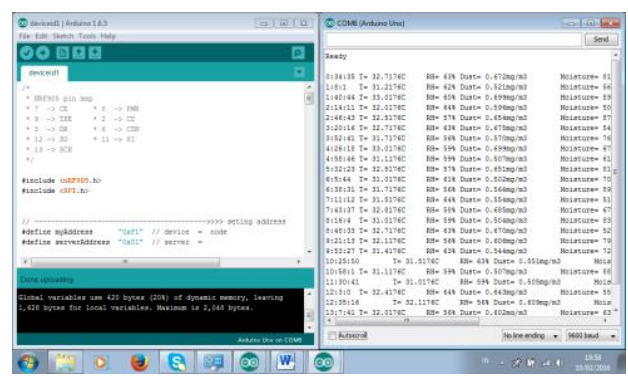

Gambar 18 Tampilan serial monitor di node sensor 1

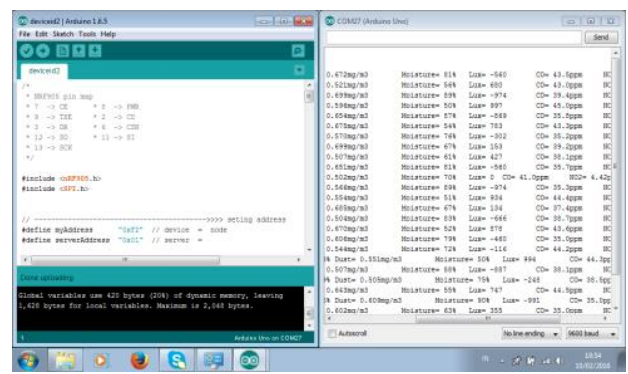

Gambar 19 Tampilan Serial Monitor di node sensor 2

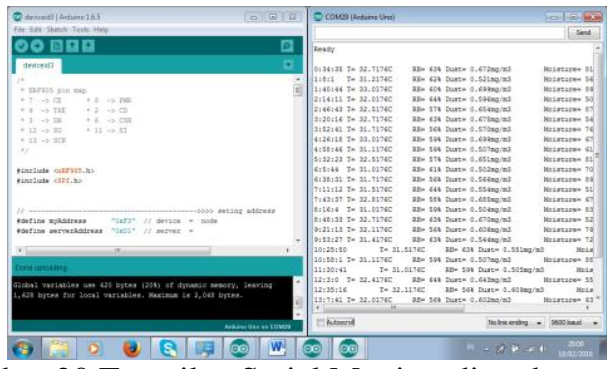

Gambar 20 Tampilan Serial Monitor di node sensor 3

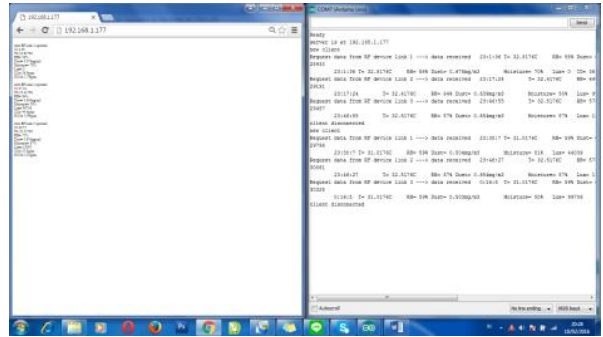

Gambar 21 node koordinator menerima data dan mengirim ke web browser

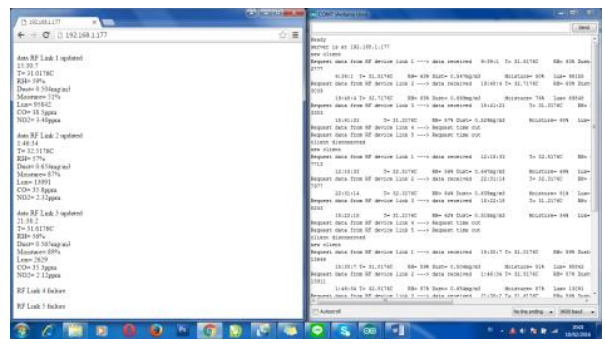

Gambar 22 node koordiinator dengan pesan "request timeout" web browser "failure"

Pengujian metode kedua akan dilakukan pengamatan dengan cara menambah node sensor yang akan di terima oleh node koordinator dalam waktu 1 detik dan di kirim ke web browser setiap 5 detik. Jumlah node sensor pada node koordinator akan ditambah setiap kelipatan 3 untuk node sensor . Dimana pada saat ditambahkan setiap kelipatan 3 di lihat apakah node koordinator dapat mengirim data ke web browser. Hasil pengamatan dapat dilihat pada Tabel 3 menunjukkan berapa banyak node sensor yang dapat terhubung ke node koordinator.

Tabel 3 banyak node sensor yang terhubung ke node koordinator dalam waktu 1 detik dan terkirimke web browser.

\begin{tabular}{|l|l|l|l|l|}
\hline No & $\begin{array}{c}\text { Jumlah } \\
\text { node }\end{array}$ & $\begin{array}{c}\text { Node } \\
\text { koordinator }\end{array}$ & Web browser & status \\
\hline 1 & 3 & Data terkirim & Data diterima & valid \\
\hline 2 & 6 & Data terkirim & Data diterima & valid \\
\hline 3 & 9 & Data terkirim & Data diterima & valid \\
\hline 4 & 12 & Data terkirim & Data diterima & valid \\
\hline 5 & 15 & Data terkirim & Data diterima & valid \\
\hline 6 & 18 & Data terkirim & Data diterima & valid \\
\hline 7 & 21 & Data terkirim & Data diterima & valid \\
\hline 8 & 22 & Data terkirim & Data diterima & valid \\
\hline 9 & 23 & Data terkirim & Tidak ada data & Tidak valid \\
\hline 10 & 24 & Data terkirim & Tidak ada data & Tidak valid \\
\hline
\end{tabular}

Hasil pengujian pada Tabel 3 menunjukkan bahwa dengan jumlah node 22 data dapat dikirim ke web browser 
sedangkan dengan jumlah node 23 data yang tampil di node koordinator "tidak valid" dan data tersebut tidak dapat dikirim ke web browser. Sehingga dapat disimpulkan maksimum jumlah node yang terhubung ke node koordinator yang kemudian di kirimkan ke web browser melalui Ethernet Shild dalam waktu satu detik ialah sebanyak 22 node, dari pengujian ini dapat disimpulkan bahwa dalam mengirim 1 node sensor dibutuhkan payload 434 bit jadi untuk mengirimkan data 22 node sensor dalam waktu 1 detik adalah 9548 bps dimana dalam mengirimkan data 22 node sensor menggunakan 9600 bps jadi jumlah overhead saat mengirimkan data 22 node 52 bps dan waktu minimum yang dibutuhkan untuk mengirimkan dan menerima data dari 1 node sensor ialah 45 milidetik atau 0.045 detik.

\subsection{2 pengujian keandalan sistem}

Sistem di uji berdasarkan 10 data yang dikirim dari node sensor ke node koordinator dalam beberapa jangkauan dimulai dari jangkauan 70 meter sampai dengan 250 meter. Hasil pengiriman data dilihat melalui serial monitor. Pengujian dimulai dengan komunikasi antara node koordinator dan node sensor .Pengujian jarak antara node koordinator dan node sensor dapat dilihat pada tabel 4 berikut.

Tabel 4 Jarak antara node sensor dengan node koordinator.

\begin{tabular}{|l|l|l|l|l|l|l|}
\hline no & $\begin{array}{l}\text { Jarak( } \\
\text { meter) }\end{array}$ & $\begin{array}{l}\text { Node } \\
\text { Sensor } \\
1\end{array}$ & $\begin{array}{l}\text { Node } \\
\text { sensor } \\
2\end{array}$ & $\begin{array}{l}\text { Node } \\
\text { sensor } \\
3\end{array}$ & $\begin{array}{l}\text { Node } \\
\text { sensor } \\
4\end{array}$ & $\begin{array}{l}\text { Node } \\
\text { sensor } \\
5\end{array}$ \\
\hline 1 & 70 & $100 \%$ & $100 \%$ & $100 \%$ & $100 \%$ & $100 \%$ \\
\hline 2 & 100 & $100 \%$ & $100 \%$ & $100 \%$ & $100 \%$ & $100 \%$ \\
\hline 3 & 130 & $100 \%$ & $100 \%$ & $100 \%$ & $100 \%$ & $100 \%$ \\
\hline 4 & 160 & $100 \%$ & $100 \%$ & $100 \%$ & $100 \%$ & $100 \%$ \\
\hline 5 & 190 & $100 \%$ & $100 \%$ & $100 \%$ & $100 \%$ & $100 \%$ \\
\hline 6 & 220 & $100 \%$ & $100 \%$ & $100 \%$ & $100 \%$ & $100 \%$ \\
\hline 7 & 240 & $100 \%$ & $100 \%$ & $100 \%$ & $100 \%$ & $100 \%$ \\
\hline 8 & 245 & $100 \%$ & $100 \%$ & $100 \%$ & $100 \%$ & $100 \%$ \\
\hline 9 & 246 & $60 \%$ & $90 \%$ & $100 \%$ & $100 \%$ & $80 \%$ \\
\hline 10 & 247 & $60 \%$ & $70 \%$ & $100 \%$ & $100 \%$ & $60 \%$ \\
\hline 11 & 248 & $40 \%$ & $30 \%$ & $50 \%$ & $100 \%$ & $30 \%$ \\
\hline 12 & 249 & $10 \%$ & $10 \%$ & $20 \%$ & $40 \%$ & $20 \%$ \\
\hline 13 & 250 & $0 \%$ & $0 \%$ & $0 \%$ & $0 \%$ & $0 \%$ \\
\hline
\end{tabular}

Hasil persentase keberhasilan pengiriman data dapat disimpulkan bahwa untuk mendapatkan sistem yang baik dalam komunikasi jaringan sensor nirkabel kita perlu memperhatikan rata-rata jangkauan sub sistem untuk menjadi acuan. Pada pengujian sistem jaringan sensor nirkabel nilai $\mathrm{L}_{\min }$ adalah 245 meter dan $\mathrm{L}_{\max }$ untuk node sensor 1 adalah 245 meter, node sensor 2 adalah 245 meter, node sensor 3 adalah 247 meter, node sensor 4 adalah 248 meter, node sensor 5 adalah 245 meter. Sistem komunikasi pengiriman data menggunakan nRF905 dikatakan kurang handal karena berbeda 755 meter dari jangkauan maksimal 1000 meter di datasheet.

Adanya perbedaan jangkauan komunikasi antara node sensor 1 dengan yang lain terletak pada modul komunikasinya, dalam hal ini nRF905. Faktor-faktor yang mempengaruhi komunikasi adalah frekuensi, TX gain, sensitivitas RX, dan interferensi sinyal.
Frekuensi pada sistem tidak berpengaruh karena modul komunikasi yang digunakan itu sama yaitu nRF905, sehingga faktor-faktor yang dimungkinkan yang mempengaruhi jangkauan TX gain, sensitivitas RX dan interferensi sinyal pada modul komunikasi tersebut dan daya untuk masing masing sensor.

Perbedaan jangkauan komunikasi antar node sensor yang satu dengan yang lain dapat dijadikan pertimbangan dalam pengambilan keputusan jangkauan maksimal saat pengimplementasian sistem. Mengingat jangkaun maksimal masing-masing node berbeda, maka pengambilan keputusan jangkauan maksimal saat pengimplemtasian sistem didasarkan pada jangakauan maskimal dimana kelima node mampu berkomunikasi dengan baik.

\section{PENUTUP}

\section{a. Kesimpulan}

Dari hasil pengujian yang dilakukan terhadap sistem jaringan sensor nirkabel untuk memantau suhu dan kelembaban, maka dapat disimpulkan sebagai berikut :

1. Node sensor dapat berjalan dengan baik berdasarkan fungsi dan keandalan sistem. Hal ini ditunjukkan dengan node sensor dapat menerima permintaan data dari node koordinator dan dapat mengirim data sensor PM2.5, $\mathrm{CO}, \mathrm{NO} 2, \mathrm{HC}$, intensitas cahaya, suhu dan kelembapan ke node koordinator dan node koordinator dapat membedakan id masing - masing node sensor.

2. Node koordinator dapat berjalan dengan baik berdasarkan fungsi dan keandalan sistem. Hal ini ditunjukkan dengan:

a. Node koordinator dapat mengirim permintaan data ke node sensor dan dapat menerima data sensor PM2.5, $\mathrm{CO}, \mathrm{NO} 2, \mathrm{HC}$, intensitas cahaya, suhu dan kelembapan dari node sensor dan mampu membedakan data data dari masing masing node sensor.

b. node koordinator dapat mendeteksi jumlah node sensor maksimum yang dapat diterima kemudian dikirim ke web browser yaitu sebanyak 22, dimana untuk mengirimkan data 22 node sensor payloadnya ialah 9548bps dan untuk mengirimkan dan menerima data dari 1 node sensor ialah 45 milidetik atau 0.045 detik.

c. Data yang ditampilkan di web browser telah sesuai dengan data yang ditampilkan di serial monitor pada sisi node koordinator.

3. Komunikasi dari sistem jaringan sensor nirkabel ini mampu berjalan dengan baik. Hal ini ditunjukkan dengan modul nRF905 merupakan modul komunikasi data yang handal untuk mengirimkan data dengan $\mathrm{L}_{\min } 245$ meter. 
b. Saran

Berdasarkan hasil pengujian dan pengukuran yang dilakukan terhadap jaringan sensor nirkabel untuk memantau sensor PM2.5, CO, NO2, HC, intensitas cahaya, suhu dan kelembapan menggunakan NRF905, dapat diberikan beberapa saran untuk pengembangan yang dapat dilakukan pada tugas akhir ini yaitu :

1. Sistem ini dapat dikembangkan menggunakan menggunakan modul komunikasi selain nRF905 agar dapat mengirimkan jarak yang lebih jauh pada suatu area.

2. Halaman web yang ada pada sistem ini dapat dikembangkan dalam bentuk sistem informasi lebih lanjut sehingga data dapat diolah dan dianalis serta diinterpretasikan dalam bentuk grafik.

3. Sistem ini dapat dikembangkan untuk multinode sensor yang berjumlah 100 atau lebih dengan memprtimbangkan boud pada node sensor dan koordinator

\section{DAFTAR PUSTAKA}

[1] A. T. Tugaswatii, "Emisi Gas Buang Kendaraan Bermotor dan Dampaknya Terhadap Kesehatan,” 2004.

[2] n. pohan, "Pencemaran Udara dan Hujan Asam," pp. 114, 2002.

[3] A. A. Machfud, "sistem pemantauan tanaman berbasis Jaringan sensor nirkabel untuk aplikasi greenhouse," tesis, pp. 8-30, 2008.

[4] w. hijau, "perencanaan dan pengembangan wilayah," vol. 1, no. 1, pp. 1-144, 2005.

[5] D. ardyanto, "perancangan perangkat transfer data file komputer terenkripsii secara hardware menggunakan media wireless dan mikrokontroler AVR

ATMEGA162" makalah tu as akhir, . 1-8 2013.

[6] D. I. Af'idah, A. F. Rochim, dan E. D. Widianto, "Peran cangan Jaringan Sensor Nirkabel (JSN) untuk Memantau Suhu dan Kelembaban Menggunakan nRF24L01+," Jur nal Teknologi dan Sistem Komputer, vol. 2, no. 4, 2014

[7] p. u. s. m. (UNS), "green campus," digilab.uns.ac.id, 2015. 